

\title{
Value of Life and Annuity Demand
}

\author{
Svetlana Pashchenko, and Ponpoje Porapakkarm*
}

May 30, 2020

\begin{abstract}
How does the value of life affect annuity demand? To address this question, we construct a portfolio choice problem with three key features: i) agents have access to life-contingent assets, ii) they always prefer living to dying, iii) agents have nonexpected utility preferences. We show that as utility from being alive increases, annuity demand decreases (increases) if agents are more (less) averse to risk rather than to intertemporal fluctuations. Put differently, if people prefer early resolution of uncertainty, they are less interested in annuities when the value of life is high. Our findings have two important implications. First, we get a better understanding of the well-known annuity puzzle. Second, we argue that the observed low annuity demand provides evidence that people prefer early rather than late resolution of uncertainty.
\end{abstract}

Keywords: annuities, value of a statistical life, portfolio choice problem, life-contingent assets, longevity insurance

JEL Classification Codes: D91, G11, G22

*Pashchenko: University of Georgia, email: svetlanap.econ@gmail.com. Porapakkarm: National Graduate Institute for Policy Studies (GRIPS), email: p-porapakkarm@grips.ac.jp. Thor Watson provided excellent research assistance. 


\section{Introduction}

How does the value of life affect investments in life-contingent assets? Standard portfolio choice theory with survival uncertainty, going back to Yaari (1965), usually sidesteps the issue of the value of life by not requiring the agent's utility when alive to be greater than when he is dead. ${ }^{1}$ Empirical evidence shows, however, that people require substantial compensation for an increase in mortality risk, implying that the value of life is large (see Viscusi, 1993, for an extensive review). This, in turn, has dramatic effects on the welfare assessment of issues involving changes in health and longevity (Murphy and Topel, 2006; Hall and Jones, 2007).

Our goal in this paper is to analyze a portfolio choice problem in an environment where life is valuable but survival is uncertain. Specifically, we study how explicitly incorporating the value of life changes our understanding of consumers' decisions to invest in assets with survival-contingent payoffs such as annuities or life insurance.

The starting point of such an analysis is how to think about the utility of life. We take a stand that this utility is an additional component to overall utility that depends only on whether an individual is alive but not on his consumption, income, asset holding, etc. Put differently, intra-period utility from being alive represents a non-pecuniary element of an individuals' welfare not captured by other pecuniary factors. ${ }^{2}$

In a standard additive expected utility framework, this non-pecuniary felicity from being alive does not change consumption/savings decisions because it does not affect the marginal utilities of consumption or wealth. However, this is not necessarily the case with a more general preferences specification. In our analysis, we adopt a non-expected utility framework (Kreps and Porteus, 1978). The attractive feature of these preferences is that unlike the standard expected utility case, they allow to separately model aversion to risk

\footnotetext{
${ }^{1}$ In fact, in many parametrizations of such models, people have higher utility in the state of death. This happens, for example, if utility over consumption is of the constant relative risk aversion (CRRA) type with the coefficient of risk aversion set above one, and the utility in death is set equal to zero.

${ }^{2}$ In this approach, we follow Hall and Jones (2007). An alternative approach is to re-normalize disutility from being dead instead of assuming extra utility from being alive. Rosen (1988) shows that these two approaches are equivalent.
} 
and aversion to intertemporal substitution. This feature adds an important dimension to the analysis: even though the utility from being alive does not affect the intra-period marginal utility, it does introduce additional fluctuations in utility both over time and over states of the world. This, in turn, matters for decisions of consumers who have different attitudes towards these two types of fluctuations.

In this framework, we study how consumers allocate their investments between survivalcontingent assets. In the standard expected utility framework, the trade-off in this decision depends on the marginal benefits of having additional resources in each state: marginal utility of consumption if alive and marginal utility of bequests if dead. In the non-expected utility case, there is an additional consideration, which, following Weil (1990), we call the trade-off between safety and stability of utility. Importantly, each life-contingent asset can potentially affect this trade-off in a different way.

We proceed in several steps. First, we provide a general characterization of how changes in (intra-period) utility of being alive affect the relative benefits of allocating resources to states when alive versus when dead. We derive conditions that determine the sign of the corresponding change in annuity demand. We show that if agents are more (less) averse to risk than to intertemporal fluctuations, annuity demand decreases (increases) when intra-period utility of being alive increases. This happens because an increase in intra-period utility from being alive increases differences in utilities both across states of the world and over time. Annuity investments accentuate the former difference but can smooth the latter.

Second, in the same general framework, we turn to the concept of the value of a statistical life (VSL), which represents the willingness to pay to marginally reduce mortality risk and is commonly used in the health and longevity literature (e.g., Cordoba and Ripoll, 2017). We show that the relationship between intra-period utility of being alive and VSL is not necessarily positive. A negative relationship can arise when preferences are such that intertemporal fluctuations are disliked more than risk. As mentioned above, this also coincides with the situation where people invest more in annuities as intra-period utility of being alive increases. Thus, when agents prefer stability over safety, the following somewhat paradoxical result can arise: as felicity from being alive increases, people are willing to pay less to extend their life, but at the same time they reallocate their portfolios towards assets 
that pay off only when they are alive.

Third, we apply our analysis to the parametrization of non-expected utility suggested by Epstein and Zin (1989), and Weil (1990). ${ }^{3}$ We show that annuity demand decreases (increases) with intra-period utility of being alive if the coefficient of relative risk aversion is higher (lower) than the inverse of the elasticity of intertemporal substitution (IES). Note that the relationship between these two parameters determines agents' attitudes toward the timing of the resolution of uncertainty. Our result, thus, can be restated as follows: when agents prefer early (late) resolution of uncertainty, they are less (more) interested in annuities as intra-period utility of being alive increases.

In the final part of the paper, we provide a quantitative illustration of our theoretical findings using a retirement saving model where agents have access to the private annuity market. Using the distribution of retirees by wealth and pension income from the Health and Retirement Study (HRS), we simulate how annuity demand changes with the value of life. We show that if risk aversion is above the inverse of the IES, the percentage of people buying annuities quickly decreases as the VSL increases. Moreover, the demand for annuities is almost completely eliminated even for relatively low values of VSL. Put differently, when people prefer early resolution of uncertainty, the low demand for annuities can to a significant extent be accounted for by the fact that people derive utility from being alive, and to arrive to this result we do not need unrealistically high values of VSL.

The last result offers important insight into the long-standing annuity puzzle. The essence of this puzzle is that a standard life-cycle model predicts people should annuitize a substantial fraction (if not all) of their wealth (Yaari, 1965), while in reality, the demand for annuities is low. A number of explanations have been put forward to account for this discrepancy. The prominent explanations include, for example, bequest motives, market frictions, crowding out by Social Security, and high degree of impatience (Dushi and Webb, 2004; Mitchell et al., 1999; Lockwood, 2012; Pashchenko, 2013; Pashchenko and Porapakkarm, 2019). We explore another explanation for this puzzle. Specifically, we show theoretically that demand for annuities is affected by the interplay between i) agents'

\footnotetext{
${ }^{3}$ This parametrization is commonly used in macroeconomics and finance, e.g., Guvenen, 2009; Inkman et al., 2011; Kaplan and Violante, 2014; Krueger and Ludwig, 2019; Love, 2017.
} 
attitudes toward uncertainty and intertemporal fluctuations; and ii) intra-period utility of being alive. Moreover, our simulations show that this mechanism is quantitatively important.

From another angle, we can also say that in light of our findings, the low demand for annuities can be considered as evidence that people prefer early resolution of uncertainty. The issue of whether empirical evidence supports preferences for early or late resolution of uncertainty is not entirely resolved. On the one hand, support for early resolution of uncertainty comes from three sources. First are the direct estimates of the risk aversion and the elasticity of intertemporal substitution from consumption data using an Euler equation. These estimates find that the former exceeds the inverse of the latter (Attanasio and Weber, 1989; Chen et al., 2013; Vissing-Jorgensen and Attanasio, 2003). Second are the results from controlled experiments where people choose between different lotteries and preferences are elicited from their choices. These experiments show that even though people have heterogeneous preferences, on average they prefer early resolution (Brown and Kim, 2014; Meissner and Pfeiffer, 2018). Finally, studies in macro-finance show that in order to account for a numbers of features of asset markets, such as the equity premium puzzle, people should prefer early resolution of uncertainty (Bansal and Yaron, 2004; Huang and Shaliastovich, 2013; Malloy et al., 2009; Yogo, 2006).

On the other hand, evidence that people may prefer late resolution of uncertainty comes from studies in health economics. A number of studies in this field show that people avoid learning about the true state of their health when it comes to serious illness (see, for example, Oster et al., 2013 for the case of genetic testing for Huntington disease or Kellerman et al., 2002 for HIV testing; see also Cordoba and Ripoll, 2017 for an excellent review of such evidence).

It is important to mention our relationship to several strands of literature not discussed above. Our paper belongs to a broad class of studies on saving and portfolio choice in the presence of survival uncertainty. These studies can be divided into four groups based on whether mortality is assumed to be exogenous or endogenous, and whether preferences are standard additive expected utility or of a more general type.

The literature in the first category (exogenous mortality and standard preferences) is very substantial and includes, among others, seminal work on saving behavior (Hubbard et 
al., 1994; De Nardi et al., 2010). As we mentioned earlier, these studies typically abstract from the value of life; i.e., they do not impose a constraint that individuals are better off being alive since, in the context of standard preferences and exogenous mortality, assuming life is valuable usually does not add any new insights. One exception is De Nardi et al. (2018) who explicitly incorporate the value of life in a structural consumption/saving model with exogenous mortality in order to understand the non-pecuniary implications of deteriorating health.

Among the literature in the second category (exogenous mortality and non-standard preferences) it is more common to encounter studies that incorporate the value of life. This happens because more general preferences oftentimes lead to non-trivial implications of treating life as valuable. For example, Bommier and Villeneuve (2012) show that in a model with standard preferences people are risk-neutral to mortality risk, and allowing for non-additive preferences can introduce mortality risk aversion which is important to take into account in many policy applications. Cordoba and Ripoll (2017) provide a detailed illustration of the advantages of using a non-expected utility approach when modeling the value of life.

In the last two categories of studies (with endogenous mortality) incorporating the value of life is crucial because otherwise agents will deliberately increase their mortality. A common approach in this literature, starting from the seminal work of Hall and Jones (2007), is to add a constant to an otherwise standard utility function to ensure life is preferred to death (Eslami and Karimi, 2019; Fonseca et al., 2020; Nygaard, 2019; Ozkan, 2017). An alternative approach is to assume that death happens when health declines below a certain level while assuming health enters the utility function as a necessary good (Yogo, 2016).

The rest of the paper is organized as follows. Section 2 describes the environment and derives our main results. Section 3 uses an Epstein-Zin-Weil parametrization to derive restrictions on parameters that follow from our results. Section 4 provides a quantitative illustration. Section 5 concludes. 


\section{Model}

We start by considering the demand for annuities in an environment with a general preferences specification that allows us to separately characterize agents' attitudes towards fluctuations in utility across states of the world and over time. In the first step of our analysis, we do not impose parametric assumptions on preferences but rather show how demand for annuities depends on general properties of these preferences when individuals derive utility from being alive.

\section{$2.1 \quad$ Preferences}

Consider an environment where agents' preferences are characterized by a triple of functions $(w, f, g)$, where $w(\cdot)$ is the intra-period utility function, $g(\cdot)$ determines the intertemporal aggregation rule and $f(\cdot)$ determines the uncertainty aggregation rule.

We assume that aggregation both over time and over states of the world has a form of quasi-arithmetic mean. This can be defined as follows: the quasi-arithmetic mean of two numbers $x_{1}$ and $x_{2}$ using function $h(\cdot), M_{h}$, is:

$$
M_{h}\left(x_{1}, x_{2}\right)=h^{-1}\left[\gamma h\left(x_{1}\right)+(1-\gamma) h\left(x_{2}\right)\right]
$$

where $h(\cdot)$ is strictly monotone and $0<\gamma<1^{4}$

Using this definition and denoting the value function of an agent at time $t$ as $V_{t}$, we can write the preferences in recursive form as follows:

$$
V_{t}=M_{g}\left(w, z_{t+1}\right)=g^{-1}\left[(1-\beta) g(w)+\beta g\left(z_{t+1}\right)\right],
$$

where $\beta$ is the discount factor and $z_{t+1}$ is the certainty equivalent:

$$
z_{t+1}=M_{f}\left(V_{t+1}^{1}, \ldots, V_{t+1}^{I}\right)=f^{-1}\left[\sum_{i=1}^{I} p_{i} f\left(V_{t+1}^{i}\right)\right]
$$

Here, $p_{i}$ is the probability of outcome $i$ next period resulting in the value function $V_{t+1}^{i}$, $i=1, \ldots, I$.

\footnotetext{
${ }^{4}$ Note that if $\gamma=\frac{1}{2}$ and $h(x)=x, M_{h}\left(x_{1}, x_{2}\right)$ is just an arithmetic mean.
} 
We assume that $w(\cdot)$ is continuous, and $f(\cdot)$ and $g(\cdot)$ are strictly increasing, concave and twice continuously differentiable. ${ }^{5}$

Before we proceed, it is important to note the followings regarding our preferences structure. First, when $f(\cdot)=g(\cdot)$, we are dealing with the standard expected utility case. Second, when $f(\cdot) \neq g(\cdot)$, we can disentangle agents' attitudes towards inter- and intratemporal utility fluctuations. Specifically, an agent's attitude toward utility fluctuations over time is determined by the function $g(\cdot)$, while his attitude toward utility fluctuations across states of the world is determined by the function $f(\cdot) .{ }^{6}$ Following Traeger $(2014)$, we can define the disentangled coefficient of relative risk aversion as:

$$
R A(x)=-\frac{\partial^{2} f(x)}{\partial x^{2}} x
$$

and the inverse of the elasticity of intertemporal substitution as:

$$
I E S^{-1}(x)=-\frac{\partial^{2} g(x)}{\partial x^{2}} x .
$$

\subsection{Portfolio choice problem}

To illustrate how the value of life can affect demand for annuities, we incorporate the preferences described above into a portfolio choice problem. There is only one type of uncertainty, which is the uncertainty in survival: with probability $s_{t}$ an agent is still alive in period $t+1$ (conditional on being alive in period $t$ ), and with probability $1-s_{t}$ he is dead in period $t+1$. Denote the corresponding value functions as $V_{t+1}^{a}$ and $V_{t+1}^{d}$, respectively.

Assume that an agent can invest in two state-contingent assets. The first type of asset delivers gross return $R_{t+1}^{a}$ next period if an agent is alive and nothing otherwise, while the

\footnotetext{
${ }^{5}$ As an example, consider two well-known parametrizations of the non-expected utility preferences commonly used in macroeconomics and finance. The first is Epztein-Zin-Weil parametrization (discussed in detail in Section 3), where both $g(\cdot)$ and $f(\cdot)$ are assumed to be constant elasticity of substitution functions. The second is risk-sensitive preferences (Hansen and Sargent, 1995), where $g(x)=x$ and $f(x)=-\frac{1}{k} \exp (-k x)$.

${ }^{6}$ It is important to stress that $g(\cdot)$ determines an agent's attitude toward intertemporal utility fluctuations. His attitude toward intertemporal consumption fluctuations depends not only on $g(\cdot)$ but also on the intra-period utility function $w(\cdot)$.
} 
second type of asset delivers gross return $R_{t+1}^{d}$ only in the state when an agent is dead and nothing otherwise. ${ }^{7}$ Denote the current holding of Type 1 assets as $k_{t}^{a}$ and of Type 2 assets as $k_{t}^{d}$.

Note that if an agent does not place any value on having assets in the state when he is dead, the portfolio choice problem becomes trivial as he will allocate $100 \%$ of his resources to Type 1 assets. We assume that agents have a bequest motive; and we denote utility from leaving a bequest in the amount $k_{t}^{d}$ as $\mho\left(k_{t}^{d}\right)$, where $\mho(\cdot)$ is increasing and continuously differentiable. We further assume that bequest is a luxury good, thus $\mho(0)=\underline{\vartheta}>-\infty .^{8}$

Denoting an agent's time $t$ consumption as $c_{t}$, we can summarize the environment as follows: if alive, an agent derives utility from consuming $c_{t}$; otherwise, he enjoys utility from leaving a bequest $k_{t}^{d} R_{t}^{d}$.

To ensure that a state when an agent is alive always brings higher utility than a state when he is dead, we assume that being alive brings additional utility. ${ }^{9}$ We model this additional utility by introducing a constant $b$, such that when $b=0$, we go back to the standard framework where life is not necessarily valuable, and $\partial V_{t}^{a} / \partial b>0$, i.e., the higher is $b$, the more valuable it is to be alive.

We specify the intra-period utility as follows:

$$
w(\cdot)= \begin{cases}\psi\left(c_{t}, b\right) & \text { if an agent is alive in period } t \\ \mho\left(k_{t}^{d}\right) & \text { otherwise } 10\end{cases}
$$

\footnotetext{
${ }^{7}$ The type 1 asset can be thought of as an annuity and the Type 2 asset as life insurance. A more common approach in the literature is to study the demand for annuities in the environment when people can invest in regular risk-free bonds as an alternative to annuity. Our results can easily be extended to that framework as well (as we will show later); however, our specification allows for a clearer illustration.

${ }^{8}$ This assumption is common in the literature since otherwise even the poorest agents are compelled to leave a bequest (see De Nardi, 2004).

${ }^{9}$ Note that without this assumption, it is not guaranteed that an agent who is alive has higher utility than an agent who dies, i.e., life is not necessarily valuable. For example, assuming CRRA utility over consumption and setting $\underline{\mho}=0$, we have a situation where an agent who left no bequest has utility equal to zero when he dies and negative utility when he is alive (assuming the coefficient of relative risk aversion is greater than one).

${ }^{10}$ Note that the actual amount of bequeathed assets is $k_{t}^{d} R_{t}^{d}$. We omit $R_{t}^{d}$ in the bequest function to make notation less cumbersome.
} 
We assume that $\frac{\partial g\left(\psi\left(c_{t}, b\right)\right)}{\partial c_{t}}$ does not depend on $b$, i.e., the g-transformed marginal utility of consumption does not depend on $b$. We will show below that this assumption ensures that in the standard expected utility framework, parameter $b$ does not affect consumption/savings decisions.

Denoting per-period income of an agent as $y_{t}$, we can write the individual's optimization problem as follows:

$$
\begin{array}{ll} 
& V_{t}^{a}\left(k_{t}^{a}\right)=\max _{k_{t+1}^{a}, k_{t+1}^{d}}\left\{g^{-1}\left[(1-\beta) g\left(\psi\left(c_{t}, b\right)\right)+\beta g\left(z_{t+1}\right)\right]\right\} \\
& z_{t+1}=f^{-1}\left[s_{t} f\left(V_{t+1}^{a}\left(k_{t+1}^{a}\right)\right)+\left(1-s_{t}\right) f\left(V_{t+1}^{d}\left(k_{t+1}^{d}\right)\right)\right] \\
\text { s.t } \quad & c_{t}+k_{t+1}^{a}+k_{t+1}^{d}=k_{t}^{a} R_{t}^{a}+y_{t} \\
& V_{t}^{d}\left(k_{t}^{d}\right)=g^{-1}\left[(1-\beta) g\left(\mho\left(k_{t}^{d}\right)\right)\right] 11
\end{array}
$$

For the ease of exposition, we introduce the following notations:

$$
\begin{aligned}
& \psi\left(c_{t}, b\right) \equiv \psi_{t}, \quad \mho\left(k_{t}^{d}\right) \equiv \mho_{t}, \\
& s_{t} f\left(V_{t+1}^{a}\left(k_{t+1}^{a}\right)\right)+\left(1-s_{t}\right) f\left(V_{t+1}^{d}\left(k_{t+1}^{d}\right)\right) \equiv m_{t+1} .
\end{aligned}
$$

Using these notations, we can write the first-order conditions for the investments in $k_{t+1}^{a}$ and $k_{t+1}^{d}$ as follows:

$$
\begin{aligned}
& (1-\beta) \frac{\partial g\left(\psi_{t}\right)}{\partial c_{t}}=\beta \frac{\partial g\left(z_{t+1}\right)}{\partial z_{t+1}} \frac{\partial f^{-1}\left(m_{t+1}\right)}{\partial m_{t+1}} s_{t} \frac{\partial f\left(V_{t+1}^{a}\right)}{\partial V_{t+1}^{a}} \frac{\partial V_{t+1}^{a}}{\partial k_{t+1}^{a}}, \\
& (1-\beta) \frac{\partial g\left(\psi_{t}\right)}{\partial c_{t}}=\beta \frac{\partial g\left(z_{t+1}\right)}{\partial z_{t+1}} \frac{\partial f^{-1}\left(m_{t+1}\right)}{\partial m_{t+1}}\left(1-s_{t}\right) \frac{\partial f\left(V_{t+1}^{d}\right)}{\partial V_{t+1}^{d}} \frac{\partial V_{t+1}^{d}}{\partial k_{t+1}^{d}} .
\end{aligned}
$$

\footnotetext{
${ }^{11}$ We can also set $V_{t}^{d}\left(k_{t}^{d}\right)=\mho\left(k_{t}^{d}\right)$, which will not change our results. We have chosen this formulation for the sake of symmetry.
} 
We can use the envelop theorem to find $\partial V_{t+1}^{a} / \partial k_{t+1}^{a}$ and $\partial V_{t+1}^{d} / \partial k_{t+1}^{d}$ :

$$
\begin{aligned}
& \frac{\partial V_{t+1}^{a}}{\partial k_{t+1}^{a}}=\frac{(1-\beta) \partial g\left(\psi_{t+1}\right) / \partial c_{t+1} R_{t+1}^{a}}{\partial g\left(V_{t+1}^{a}\right) / \partial V_{t+1}^{a}}, \\
& \frac{\partial V_{t+1}^{d}}{\partial k_{t+1}^{d}}=\frac{(1-\beta) \partial g\left(\mho_{t+1}\right) / \partial k_{t+1}^{d} R_{t+1}^{d}}{\partial g\left(V_{t+1}^{d}\right) / \partial V_{t+1}^{d}} .
\end{aligned}
$$

Note that the left-hand sides of Equation (1) and Equation (2) are the marginal costs of investing in $k_{t+1}^{a}$ and $k_{t+1}^{d}$, respectively, while the right-hand sides represent the corresponding marginal benefits. We denote these marginal benefits as $M B_{t+1}^{a}$ and $M B_{t+1}^{d}$ for investment in $k_{t+1}^{a}$ and $k_{t+1}^{d}$, respectively.

The key object of interest for our analysis is the ratio $M B_{t+1}^{a} / M B_{t+1}^{d}$ since it determines the relative demand for Type 1 and Type 2 assets. Using Equation (3) and Equation (4), this ratio can be represented as follows:

$$
\frac{M B_{t+1}^{a}}{M B_{t+1}^{d}}=\frac{s_{t}}{1-s_{t}} \frac{\left(\frac{\partial f\left(V_{t+1}^{a}\right) / \partial V_{t+1}^{a}}{\partial g\left(V_{t+1}^{a}\right) / \partial V_{t+1}^{a}}\right)}{\left(\frac{\partial f\left(V_{t+1}^{d}\right) / \partial V_{t+1}^{d}}{\partial g\left(V_{t+1}^{d}\right) / \partial V_{t+1}^{d}}\right)}\left(\frac{\partial g\left(\psi_{t+1}\right) / \partial c_{t+1}}{\partial g\left(\mho_{t+1}\right) / \partial k_{t+1}^{d}}\right) \frac{R_{t+1}^{a}}{R_{t+1}^{d}} .
$$

Consider first the standard expected utility case where $f(\cdot)=g(\cdot)$. In this case, the ratio in Equation (5) reduces to:

$$
\frac{M B_{t+1}^{a}}{M B_{t+1}^{d}}=\frac{s_{t}}{1-s_{t}}\left(\frac{\partial g\left(\psi_{t+1}\right) / \partial c_{t+1}}{\partial g\left(\mho_{t+1}\right) / \partial k_{t+1}^{d}}\right) \frac{R_{t+1}^{a}}{R_{t+1}^{d}}
$$

which is just the ratio of marginal utilities of consumption and bequests multiplied by the ratio of expected returns of the two state-contingent assets.

Our key point of interest is how the ratio $M B_{t+1}^{a} / M B_{t+1}^{d}$ changes when $b$ increases, i.e., when being alive brings higher utility. If, for example, this ratio increases as $b$ increases, the marginal benefits of investing in the state when an individual is alive increases compared to the marginal benefits of investing in the state when he is dead; thus, he shifts his investments toward $k_{t+1}^{a}$. If the opposite is true, an agent reallocates toward $k_{t+1}^{d}$ as $b$ increases. ${ }^{12}$ 
Note that given our assumption that $\frac{\partial g\left(\psi_{t+1}\right)}{\partial c_{t+1}}$ does not depend on $b$, the ratio $M B_{t+1}^{a} / M B_{t+1}^{d}$ does not depend on $b$ as well, and thus the demand for annuities and portfolio allocation in general is independent of $b$ in the expected utility framework.

Let us now return to a more general case of non-expected utility $(f(\cdot) \neq g(\cdot))$ and analyze the ratio $M B_{t+1}^{a} / M B_{t+1}^{d}$ given in Equation (5). To understand how this ratio changes with $b$, we need to take the derivative. To make the analysis more transparent, we introduce the following notations:

$$
\begin{aligned}
& \frac{\partial f\left(V_{t+1}^{a}\right)}{\partial V_{t+1}^{a}} \equiv f_{a}^{\prime}, \quad \frac{\partial^{2} f\left(V_{t+1}^{a}\right)}{\partial\left(V_{t+1}^{a}\right)^{2}} \equiv f_{a}^{\prime \prime}, \\
& \frac{\partial g\left(V_{t+1}^{a}\right)}{\partial V_{t+1}^{a}} \equiv g_{a}^{\prime}, \quad \frac{\partial^{2} g\left(V_{t+1}^{a}\right)}{\partial\left(V_{t+1}^{a}\right)^{2}} \equiv g_{a}^{\prime \prime}, \\
& \frac{\partial f\left(V_{t+1}^{d}\right)}{\partial V_{t+1}^{d}} \equiv f_{d}^{\prime}, \quad \frac{\partial g\left(V_{t+1}^{d}\right)}{\partial V_{t+1}^{d}} \equiv g_{d}^{\prime}, \\
& \frac{s_{t}}{1-s_{t}}\left(\frac{\partial g\left(\psi_{t+1}\right) / \partial c_{t+1}}{\partial g\left(\mho_{t+1}\right) / \partial k_{t+1}^{d}}\right) \frac{R_{t+1}^{a}}{R_{t+1}^{d}} \equiv D
\end{aligned}
$$

Note that $D$ is a positive constant that does not depend on $b$. Using these new notations, we can write the derivative of the ratio $M B_{t+1}^{a} / M B_{t+1}^{d}$ with respect to $b$ as follows:

$$
\frac{\partial}{\partial b}\left(\frac{M B_{t+1}^{a}}{M B_{t+1}^{d}}\right)=D \frac{g_{d}^{\prime}}{f_{d}^{\prime}} \frac{f_{a}^{\prime}}{g_{a}^{\prime}} \frac{1}{\left(g_{a}^{\prime}\right)^{2}} \frac{\partial V_{t+1}^{a}}{\partial b}\left(\frac{f_{a}^{\prime \prime}}{f_{a}^{\prime}}-\frac{g_{a}^{\prime \prime}}{g_{a}^{\prime}}\right)
$$

Note that the whole expression on the right-hand side before the bracket is positive: $D>0 ; \partial V_{t+1}^{a} / \partial b>0 ;$ in addition, the pairs $\left(g_{a}^{\prime}, g_{d}^{\prime}\right)$ and $\left(f_{a}^{\prime}, f_{d}^{\prime}\right)$ have the same sign because of monotonicity of $f(\cdot)$ and $g(\cdot)$. Thus, the sign of $\frac{\partial}{\partial b}\left(M B_{t+1}^{a} / M B_{t+1}^{d}\right)$ is determined by the expression in the bracket: $\frac{f_{a}^{\prime \prime}}{f_{a}^{\prime}}-\frac{g_{a}^{\prime \prime}}{g_{a}^{\prime}}$.

\footnotetext{
${ }^{12}$ Note that if instead of two state-contingent assets, we consider portfolio allocation between annuities and regular bonds, we would consider the ratio: $M B_{t+1}^{a} /\left(M B_{t+1}^{a}+M B_{t+1}^{d}\right)$, where the denominator represents the marginal benefits of investing in bonds since they pay out both in states when an individual is alive and not alive. Since this expression can be rewritten as $1 /\left(1+M B_{t+1}^{d} / M B_{t+1}^{a}\right)$, the ratio $M B_{t+1}^{a} / M B_{t+1}^{d}$ is still our main object of interest determining the relative weight of annuities in the optimal portfolio.
} 
Given that both $f(\cdot)$ and $g(\cdot)$ are increasing and concave, both ratios $\frac{f_{a}^{\prime \prime}}{f_{a}^{\prime}}$ and $\frac{g_{a}^{\prime \prime}}{g_{a}^{\prime}}$ are negative. As discussed earlier, these ratios can be thought of as measuring an agent's aversion to fluctuations in utility over states of the world and over time, respectively.

We consider two cases here. First, if $\frac{f_{a}^{\prime \prime}}{f_{a}^{\prime}}-\frac{g_{a}^{\prime \prime}}{g_{a}^{\prime}}<0$, we can say $f(\cdot)$ is "more concave" than $g(\cdot)$. In this case, an increase in $b$ leads to more investments in $k_{t+1}^{d}$ and a decrease in demand for annuities.

In contrast, when $\frac{f_{a}^{\prime \prime}}{f_{a}^{\prime}}-\frac{g_{a}^{\prime \prime}}{g_{a}^{\prime}}>0, g(\cdot)$ is "more concave" than $f(\cdot)$ and an increase in $b$ leads to higher demand for annuities since $M B_{t+1}^{a}$ increases relative to $M B_{t+1}^{d}$.

Thus, the relative concavity of $f(\cdot)$ versus $g(\cdot)$ determines whether an increase in intraperiod utility of being alive increases or decreases the demand for annuities. We discuss the intuition behind this result in the next section.

\subsection{Why does the relative concavity of $f(\cdot)$ and $g(\cdot)$ matter?}

To better understand the results of the previous section, here we further discuss the importance of the relative concavity of functions $f(\cdot)$ and $g(\cdot)$. Our focus is on how the properties of these functions affect an agent's decision of whether to allocate an extra dollar of investment in $k_{t+1}^{a}$ (and thus increase $V_{t+1}^{a}$ ) or in $k_{t+1}^{d}$ (and thus increase $V_{t+1}^{d}$ ).

To better illustrate the intuition, we consider two extreme cases which differ in whether $f(\cdot)$ or $g(\cdot)$ is more concave. In the first case, we assume that $g(\cdot)$ is linear while maintaining the assumption that $f(\cdot)$ is concave. In the second case, we assume that $f(\cdot)$ is linear and only $g(\cdot)$ is concave.

\subsubsection{Case 1: $g(\cdot)$ is linear and $f(\cdot)$ is concave}

We can write the agent's value function as follows:

$$
V_{t}^{a}=(1-\beta) \psi_{t}+\beta M_{f}\left(V_{t+1}^{a}, V_{t+1}^{d}\right)
$$

Note that as $b$ increases, $V_{t+1}^{a}$ increases while $V_{t+1}^{d}$ does not change. Since $f(\cdot)$ is concave, the generalized f-mean $M_{f}(\cdot)$ puts higher weight on smaller outcomes. The increase in $V_{t+1}^{a}$ implies a decrease in its relative weight, i.e., its contribution to $M_{f}(\cdot)$ goes down. Thus, as 
$b$ increases, the shift in relative weight from $V_{t+1}^{a}$ to $V_{t+1}^{d}$ makes investment in $k_{t+1}^{d}$ more attractive.

More formally, using the assumption of the linearity of $g(\cdot)$, we can rewrite the ratio $M B_{t+1}^{a} / M B_{t+1}^{d}$ in Equation (5) as follows:

$$
\frac{M B_{t+1}^{a}}{M B_{t+1}^{d}}=\frac{s_{t}}{1-s_{t}}\left(\frac{\partial f\left(V_{t+1}^{a}\right) / \partial V_{t+1}^{a}}{\partial f\left(V_{t+1}^{d}\right) / \partial V_{t+1}^{d}}\right)\left(\frac{\partial g\left(\psi_{t+1}\right) / \partial c_{t+1}}{\partial g\left(\mho_{t+1}\right) / \partial k_{t+1}^{d}}\right) \frac{R_{t+1}^{a}}{R_{t+1}^{d}}
$$

Note that the only term in this expression that changes as $b$ increases is $\partial f\left(V_{t+1}^{a}\right) / \partial V_{t+1}^{a}$. Given the concavity of $f(\cdot)$, this term decreases as $V_{t+1}^{a}$ increases.

Intuitively, the function $f(\cdot)$ determines an agent's attitude toward fluctuations in utility over states of the world. An increase in $b$ widens the gap between $V_{t+1}^{a}$ and $V_{t+1}^{d}$, so an agent tries to reverse this by increasing the value of being dead $V_{t+1}^{d}$ through investments in $k_{t+1}^{d}$.

\subsubsection{Case 2: $f(\cdot)$ is linear and $g(\cdot)$ is concave}

In this case, we can write the agent's value function as follows:

$$
\begin{aligned}
& V_{t}^{a}=M_{g}\left(\psi_{t}, z_{t+1}\right), \\
& z_{t+1}=s_{t} \underbrace{M_{g}\left(\psi_{t+1}, z_{t+2}\right)}_{V_{t+1}^{a}}+\left(1-s_{t}\right) V_{t+1}^{d}
\end{aligned}
$$

Note that this time, because of the linearity of $f(\cdot)$, an increase in $b$ does not change the relative weight of $V_{t+1}^{a}$ versus $V_{t+1}^{d}$ in forming the certainty equivalence $z_{t+1}$. Instead, and in contrast to the previous case, $\psi_{t+1}$ and $z_{t+2}$ are combined non-linearly to form $V_{t+1}^{a}$ through the generalized g-mean $M_{g}(\cdot)$. In response to the increase in $b$, both $\psi_{t+1}$ and $z_{t+2}$ increase, but the increase in $z_{t+2}$ is larger because the increase in $\psi_{t+1}$ only reflects extra utility from one additional year of life, while the increase in $z_{t+2}$ reflects extra utility from multiple future years of life. Thus, the relative weight of $\psi_{t+1}$ in $V_{t+1}^{a}$ (and hence in $z_{t+1}$ ) increases, making investments in $k_{t+1}^{a}$ more attractive.

More formally, we can rewrite the ratio in Equation (5) as follows:

$$
\frac{M B_{t+1}^{a}}{M B_{t+1}^{d}}=\frac{s_{t}}{1-s_{t}}\left(\frac{\partial g\left(V_{t+1}^{d}\right) / \partial V_{t+1}^{d}}{\partial g\left(V_{t+1}^{a}\right) / \partial V_{t+1}^{a}}\right)\left(\frac{\partial g\left(\psi_{t+1}\right) / \partial c_{t+1}}{\partial g\left(\mho_{t+1}\right) / \partial k_{t+1}^{d}}\right) \frac{R_{t+1}^{a}}{R_{t+1}^{d}}
$$


Note that the only term here that depends on $b$ is $\partial g\left(V_{t+1}^{a}\right) / \partial V_{t+1}^{a}$, which decreases as $b$ increases, thus making the ratio larger.

Intuitively, the function $g(\cdot)$ determines an agent's attitude toward utility fluctuations over time, which is the only concern here given he is risk-neutral because of the linearity of $f(\cdot)$. The increase in $b$ disproportionately increases future continuation utility (represented by $z_{t+2}$ ) relative to the intra-period utility when alive $\left(\psi_{t+1}\right)$. To bring them closer together, an agent increases $\psi_{t+1}$ by investing in $k_{t+1}^{a}$.

\subsection{The value of a statistical life}

It is important to discuss how our analysis is related to the concept of the value of a statistical life (VSL). The VSL represents a monetary value of a reduction in mortality risk that would prevent one statistical death. More formally, it is the willingness to pay for a marginal reduction in mortality risk, or the marginal rate of substitution between wealth and survival probability (Andersson and Treich, 2011).

In our framework, it can be expressed as follows:

$$
V S L=\frac{\partial V_{t}^{a} / \partial s_{t}}{\partial V_{t}^{a} / \partial k_{t}^{a}}
$$

For the ease of exposition and comparison with other studies, we are going to rewrite the budget constraint in our optimization problem in terms of asset prices rather than asset returns:

$$
c_{t}+p_{t+1}^{a} k_{t+1}^{a}+p_{t+1}^{d} k_{t+1}^{d}=y_{t}+k_{t}^{a}
$$

Compared to the previous formulation, the return on assets is normalized to be equal to one (conditional on surviving), while the price of the unit of assets $k_{t+1}^{a}\left(k_{t+1}^{d}\right) \operatorname{costs} p_{t+1}^{a}$ $\left(p_{t+1}^{d}\right){ }^{13}$

To derive $\partial V_{t}^{a} / \partial s_{t}$, we need to take into account that a change in $s_{t}$ can potentially affect the price of survival-contingent assets, i.e., $\frac{\partial p_{t+1}^{i}}{\partial s_{t}}(i=a, d)$ can be nonzero.

\footnotetext{
${ }^{13}$ Assets prices and returns are linked as follows: $p_{t+1}^{a}=1 / R_{t+1}^{a}$ and $p_{t+1}^{d}=1 / R_{t+1}^{d}$.
} 
Thus,

$\frac{\partial V_{t}^{a}}{\partial s_{t}}=\beta\left(\frac{\partial g\left(z_{t+1}\right) / \partial z_{t+1}}{\partial f\left(z_{t+1}\right) / \partial z_{t+1}}\right)\left(\frac{f\left(V_{t+1}^{a}\right)-f\left(V_{t+1}^{d}\right)}{\partial g\left(V_{t}^{a}\right) / \partial V_{t}^{a}}\right)-(1-\beta) \frac{\frac{\partial g\left(\psi_{t}\right)}{\partial c_{t}}\left[k_{t+1}^{a} \frac{\partial p_{t+1}^{a}}{\partial s_{t}}+k_{t+1}^{d} \frac{\partial p_{t+1}^{d}}{\partial s_{t}}\right]}{\partial g\left(V_{t}^{a}\right) / \partial V_{t}^{a}}$

Using the envelop condition, we can write the denominator of Equation (8) as follows:

$$
\frac{\partial V_{t}^{a}}{\partial k_{t}^{a}}=(1-\beta) \frac{\partial g\left(\psi_{t}\right) / \partial c_{t}}{\partial g\left(V_{t}^{a}\right) / \partial V_{t}^{a}}
$$

Thus, ${ }^{14}$

$$
V S L=\frac{\beta}{1-\beta}\left(\frac{\partial g\left(z_{t+1}\right) / \partial z_{t+1}}{\partial f\left(z_{t+1}\right) / \partial z_{t+1}}\right)\left(\frac{f\left(V_{t+1}^{a}\right)-f\left(V_{t+1}^{d}\right)}{\left(\partial g\left(\psi_{t}\right) / \partial c_{t}\right)}\right)-k_{t+1}^{a} \frac{\partial p_{t+1}^{a}}{\partial s_{t}}-k_{t+1}^{d} \frac{\partial p_{t+1}^{d}}{\partial s_{t}}
$$

Next, consider how VSL in our model changes with $b$, the additional utility of being alive. Taking the derivative of Equation (12) with respect to $b$, we get:

$$
\begin{aligned}
\frac{\partial V S L}{\partial b} & =\frac{\beta}{1-\beta} \frac{s_{t}}{\partial g\left(\psi_{t}\right) / \partial c_{t}}\left(\frac{\partial g\left(z_{t+1}\right) / \partial z_{t+1}}{\partial f\left(z_{t+1}\right) / \partial z_{t+1}}\right) \frac{\partial f\left(V_{t+1}^{a}\right)}{\partial V_{t+1}^{a}} \frac{\partial V_{t+1}^{a}}{\partial b} \\
& \times\left\{\left(\frac{f\left(V_{t+1}^{a}\right)-f\left(V_{t+1}^{d}\right)}{\partial f\left(z_{t+1}\right) / \partial z_{t+1}}\right)\left[\left(\frac{\partial^{2} g\left(z_{t+1}\right) / \partial z_{t+1}^{2}}{\partial g\left(z_{t+1}\right) / \partial z_{t+1}}\right)-\left(\frac{\partial^{2} f\left(z_{t+1}\right) / \partial z_{t+1}^{2}}{\partial f\left(z_{t+1}\right) / \partial z_{t+1}}\right)\right]+1\right\}
\end{aligned}
$$

Similar to Equation (7) which determines whether the demand for annuities increases or decreases in $b$, the sign of the expression above depends on: ${ }^{15}$

$$
\left[\frac{\partial^{2} g\left(z_{t+1}\right) / \partial z_{t+1}^{2}}{\partial g\left(z_{t+1}\right) / \partial z_{t+1}}-\frac{\partial^{2} f\left(z_{t+1}\right) / \partial z_{t+1}^{2}}{\partial f\left(z_{t+1}\right) / \partial z_{t+1}}\right]
$$

i.e., the relative concavity of functions $g(\cdot)$ and $f(\cdot)$. When $f(\cdot)$ is more concave than $g(\cdot)$, the expression in the square bracket is positive (since both $\frac{\partial^{2} g\left(z_{t+1}\right) / \partial z_{t+1}^{2}}{\partial g\left(z_{t+1}\right) / \partial z_{t+1}}$ and

${ }^{14}$ This expression is similar to the VSL derived in Cordoba and Ripoll (2017) (Equation (17) in their paper). In their framework, they assume $V_{t+1}^{d}=0, f(x)=x^{1-\gamma}, g(x)=x^{1-\sigma}$, and $\partial p_{t+1}^{a} / \partial s_{t}=\delta /(1+r)$, where $\delta$ shows the degree of imperfection in the annuity market (with $\delta=0$ meaning the annuity market does not exist) and $(1+r)$ is the gross return on a risk-free bond.

${ }^{15}$ Note that $f\left(V_{t+1}^{a}\right)-f\left(V_{t+1}^{d}\right)$ is positive because living is preferred to dying and $f(\cdot)$ is an increasing function. 
$\frac{\partial^{2} f\left(z_{t+1}\right) / \partial z_{t+1}^{2}}{\partial f\left(z_{t+1}\right) / \partial z_{t+1}}$ are negative), thus $\partial V S L / \partial b>0$. In other words, the willingness to pay to increase the survival probability increases as life brings more utility.

Note that this is not necessarily the case when $g(\cdot)$ is more concave than $f(\cdot)$. In this situation, the expression in the square bracket is negative which can result in $\partial V S L / \partial b$ being negative. In this case, as $b$ increases, people may be willing to pay less to extend their life.

To understand the intuition behind this result, recall that the concavity of $g(\cdot)$ determines an agent's attitude toward utility fluctuations over time, i.e., his aversion to the difference between current utility $\psi_{t}$ and the certainty equivalent of future utility $z_{t+1}$. An increase in $b$ affects $z_{t+1}$ more than $\psi_{t}$ thus widening the gap between them - something an agent is trying to avoid. Moreover, the higher is the survival probability $s_{t}$, the larger is the impact of $b$ on $z_{t+1}$. Thus, when an agent's dislike for utility fluctuations over time is very high, he may be willing to pay less to increase $s_{t}$ in order to smooth these fluctuations.

Importantly, a situation where $g(\cdot)$ is more concave than $f(\cdot)$ also corresponds to the situation when demand for annuities increases as life becomes more valuable ( $b$ increases) as was shown by our analysis above. Thus, in the situation where an increase in $b$ makes an agent less willing to pay for mortality reduction, he also has higher demand for annuities. ${ }^{16}$ In other words, when we disentangle an agent's attitude towards inter- and intra-temporal utility fluctuations, the following situation can arise: as life becomes more valuable, an agent buys more annuities which further increases his utility when alive, while at the same time, he is less willing to pay to increase his survival probability.

\subsection{Extension: The case of irreversible annuity investment}

In the portfolio choice problem we have considered so far, we assume that an annuity pays out for one period: an agent, who, in period $t$, purchases an annuity gets paid only in period $t+1$; to continue receiving an annuity payout in period $t+2$, he needs to purchase an annuity again in period $t+1$. This is analogous to purchasing lifelong annuities, which

\footnotetext{
${ }^{16}$ Note, the opposite is not necessarily true. When $g(\cdot)$ is more concave than $f(\cdot)$, an agent's demand for annuities increases in $b$ but his willingness to pay for mortality reduction can still be increasing in $b$. This can be seen from Equation (13), which shows that $\partial V S L / \partial b$ can be positive in this case.
} 
can be freely adjusted both upwards and downwards every period. Annuities, however, can represent an irreversible investment: if an agent holds annuities in the amount $k_{t}^{a}$ in period $t$, he can only increase it.

To illustrate how modeling annuities as irreversible investments can affect our findings, consider the following modified portfolio choice problem. We modify the budget constraint in Equation (9) as follows:

$$
c_{t}+\tilde{p}_{t+1}^{a}\left(k_{t+1}^{a}-k_{t}^{a}\right)+p_{t+1}^{d} k_{t+1}^{d}=y_{t}+k_{t}^{a},
$$

where the annuity price $\tilde{p}_{t+1}^{a}$ takes into account the irreversibility, and is thus higher than in the case we considered earlier. ${ }^{17}$ In addition, we must add another constraint to reflect this irreversibility:

$$
k_{t+1}^{a} \geq k_{t}^{a}
$$

We denote the Lagrange multiplier on this constraint as $\mu_{t}$.

Now consider two situations. First, suppose the constraint in Equation (14) is not binding, then $\mu_{t}=0$ and our expression for $M B_{t+1}^{a} / M B_{t+1}^{d}$ is unchanged. ${ }^{18}$ Thus, our results carry through and the relative concavity of functions $f(\cdot)$ and $g(\cdot)$ determines whether demand for annuities increases or decreases as life becomes more valuable.

Second, suppose the constraint in Equation (14) is binding, $\mu_{t}>0$. In this case, in period $t$, an agent does not invest in annuities, thus at the optimum $M B_{t+1}^{a}<M B_{t+1}^{d}$. As we established earlier, when $g(\cdot)$ is more concave than $f(\cdot)$, an increase in $b$ (extra utility from being alive) increases the demand for reversible (or liquid) annuities. This, however, is not necessarily the case now: even though an increase in $b$ increases $M B_{t+1}^{a}$ relative to $M B_{t+1}^{d}$, this may not be enough to induce an agent to start investing in annuities, i.e., $M B_{t+1}^{a}$ can still be less than $M B_{t+1}^{d}$.

To summarize, when $f(\cdot)$ is more concave than $g(\cdot)$, the illiquidity of annuities does not change the result that an increase in $b$ decreases demand for annuities. When, however, $g(\cdot)$

\footnotetext{
${ }^{17}$ Note that in this specification an agent who already has lifelong annuity income $k_{t}^{a}$, adds $k_{t+1}^{a}-k_{t}^{a}$ to it in period $t$.

${ }^{18}$ Since we have rewritten the budget constraint in terms of assets prices, the ratio $R_{t+1}^{a} / R_{t+1}^{d}$ in Equation (5) is changed to $p_{t+1}^{d} / p_{t+1}^{a}$.
} 
is more concave than $f(\cdot)$, an increase in $b$ either increases the demand for annuities or has no effect on it.

Intuitively, as we discussed before, an increase in extra utility of being alive widens the gap between instantaneous utility and continuation value. An agent with a strong dislike for intertemporal utility fluctuations can partially offset this by purchasing reversible annuities. However, irreversible annuity investments have much less effect on this gap in utilities because they increase both instantaneous utility and continuation value given their lifelong payout.

\section{Illustration with Epstein-Zin-Weil preferences}

A common parametrization of non-expected utility widely used in macroeconomics and finance is to assume that both uncertainty and time aggregators are constant elasticity of substitution (CES)-type functions. This parametrization was suggested by Epstein and Zin (1989) and Weil (1990), and is referred in the literature as Epstein-Zin-Weil (EZW) preferences. In this section, we reconsider our findings using EZW parametrization of functions $f(\cdot)$ and $g(\cdot)$. We then derive the restrictions on parameters which produce decreasing or increasing demand for annuities in response to higher utility of being alive $(b)$.

We assume that:

$$
f(x)=\frac{x^{1-\sigma}}{1-\sigma}
$$

and:

$$
g(x)=\frac{x^{1-\frac{1}{\alpha}}}{1-\frac{1}{\alpha}}
$$

For the intra-period utility functions $\psi(\cdot)$ and $\mho(\cdot)$, we assume the following parametrization:

$$
\begin{aligned}
& \psi\left(c_{t}, b\right)= \begin{cases}{\left[\xi c_{t}^{\rho}+(1-\xi) b^{\rho}\right]^{1 / \rho}} & \text { if } b>0 \\
c_{t} & \text { if } b=0,\end{cases} \\
& \mho\left(k_{t}^{d}\right)=\eta\left(\varphi+k_{t}^{d} R_{t}^{d}\right)
\end{aligned}
$$


Note that when $b=0$ and $\eta=0$, we have standard EZW preferences. When $\varphi=0$, bequests become a necessity rather than a luxury. ${ }^{19}$ To maintain our assumption that $\frac{\partial g\left(\psi\left(c_{t}, b\right)\right)}{\partial c_{t}}$ does not depend on $b$, we set $\rho=1-1 / \alpha \cdot{ }^{20}$

In this parametrization, the concavity of $f(\cdot)$ is characterized by the parameter $\sigma$, which is also the coefficient of relative risk aversion, and the concavity of $g(\cdot)$ is characterized by the parameter $1 / \alpha$, which is also the inverse of the elasticity of intertemporal substitution $\alpha$. In light of our earlier results, the relationship between these two parameters is important for our subsequent analysis. Note that when $\sigma=1 / \alpha$ (and thus $f(\cdot)=g(\cdot)$ ), we are back to the standard expected utility case.

We can now write the value functions as follows:

$$
\begin{aligned}
& V_{t}^{a}\left(k_{t}^{a}\right)=\max _{k_{t+1}^{a}, k_{t+1}^{d}}\left\{(1-\beta)\left(\xi c_{t}^{1-\frac{1}{\alpha}}+(1-\xi) b^{1-\frac{1}{\alpha}}\right)+\beta z_{t+1}^{1-\frac{1}{\alpha}}\right\}^{\frac{1}{1-\frac{1}{\alpha}}} \\
& z_{t+1}=\left\{s_{t}\left[V_{t+1}^{a}\left(k_{t+1}^{a}\right)\right]^{1-\sigma}+\left(1-s_{t}\right)\left[V_{t+1}^{d}\left(k_{t+1}^{d}\right)\right]^{1-\sigma}\right\}^{\frac{1}{1-\sigma}} \\
& V_{t}^{d}\left(k_{t}^{d}\right)=\left\{(1-\beta)\left[\eta\left(\varphi+k_{t}^{d} R_{t}^{d}\right)\right]^{1-\frac{1}{\alpha}}\right\}^{\frac{1}{1-\frac{1}{\alpha}}}=(1-\beta)^{\frac{1}{1-\frac{1}{\alpha}}} \eta\left(\varphi+k_{t}^{d} R_{t}^{d}\right)
\end{aligned}
$$

s.t. $\quad c_{t}+k_{t+1}^{a}+k_{t+1}^{d}=k_{t}^{a} R_{t}^{a}+y_{t}$

Using the simplified notation introduced earlier and the envelop conditions, we can write the first-order conditions as follows:

$$
\begin{aligned}
& \xi c_{t}^{-\frac{1}{\alpha}}=\beta m_{t+1}^{\frac{1-\frac{1}{\alpha}}{1-\sigma}-1} s_{t} \xi c_{t+1}^{-\frac{1}{\alpha}} R_{t+1}^{a}\left(V_{t+1}^{a}\right)^{\frac{1}{\alpha}-\sigma} \\
& \xi c_{t}^{-\frac{1}{\alpha}}=\beta m_{t+1}^{\frac{1-\frac{1}{\alpha}}{1-\sigma}-1}\left(1-s_{t}\right) \eta^{1-\frac{1}{\alpha}}\left(\varphi+k_{t+1}^{d} R_{t+1}^{d}\right)^{-\frac{1}{\alpha}} R_{t+1}^{d}\left(V_{t+1}^{d}\right)^{\frac{1}{\alpha}-\sigma}
\end{aligned}
$$

As before, denoting the right-hand sides of Equation (15) and Equation (16) as $M B_{t+1}^{a}$ and $M B_{t+1}^{d}$, respectively, we can express the ratio of marginal benefits of investing in each

\footnotetext{
${ }^{19}$ In our parametrization of the bequest motive, we follow De Nardi (2004).

${ }^{20}$ Note that when $\rho \neq 1-1 / \alpha$, the change in $b$ affects marginal utility of consumption even in the case of standard expected utility preferences.
} 
asset as follows:

$$
\frac{M B_{t+1}^{a}}{M B_{t+1}^{d}}=\frac{s_{t}}{1-s_{t}} \frac{\xi}{\eta^{1-\frac{1}{\alpha}}} \frac{c_{t+1}^{-\frac{1}{\alpha}}}{\left(\varphi+k_{t+1}^{d} R_{t+1}^{d}\right)^{-\frac{1}{\alpha}}} \frac{R_{t+1}^{a}}{R_{t+1}^{d}} \frac{\left(V_{t+1}^{a}\right)^{\frac{1}{\alpha}-\sigma}}{\left(V_{t+1}^{d}\right)^{\frac{1}{\alpha}-\sigma}}
$$

Note that when $\frac{1}{\alpha}=\sigma$, the last term in Equation (17) disappears and the relative benefits of investing in two state-contingent assets are determined by the ratio of the marginal utility of consumption to that of bequests. In this case, a change in $b$ does not affect annuity demand.

Next, consider the case when $\frac{1}{\alpha} \neq \sigma$. The only term in Equation (17) that depends on $b$ is $\left(V_{t+1}^{a}\right)^{\frac{1}{\alpha}-\sigma}$. Taking the derivative of this term with respect to $b$, we get:

$$
\left(\frac{1}{\alpha}-\sigma\right)\left[\left(V_{t+1}^{a}\right)^{\frac{1}{\alpha}-\sigma-1}\right] \frac{\partial V_{t+1}^{a}}{\partial b}
$$

The sign of this expression is determined by $\frac{1}{\alpha}-\sigma$. When $\frac{1}{\alpha}<\sigma$, in response to an increase in $b$, agents reallocate investments from $k_{t+1}^{a}$ to $k_{t+1}^{d}$. This also corresponds to the case when $f(\cdot)$ is more concave than $g(\cdot)$ and agents dislike uncertainty more than they dislike intertemporal fluctuations. In contrast, when $\frac{1}{\alpha}>\sigma$ investments in $k_{t+1}^{a}$ increase as $b$ increases.

To summarize, when the coefficient of risk aversion is above (below) the inverse of the IES, an increase in intra-period utility of being alive, $b$, leads to lower (higher) demand for annuities.

\section{Quantitative illustration: annuitization at retirement}

In this section, we quantitatively solve a retirement saving model where retirees have access to a private annuity market. The purpose of this exercise is twofold. First, we show that utility of being alive in combination with preferences for early resolution of uncertainty is quantitatively important in explaining the annuity puzzle. Second, we argue that low annuity demand can be considered as an evidence that people have preferences for early resolution of uncertainty. 


\subsection{Setup}

A retiree enters the model at time $t=1$ with initial wealth $k_{1}$ and pension income $n_{1}$, representing pre-existing annuity income provided by Social Security. At the start of retirement, he chooses whether to acquire additional annuities through the private market, i.e., whether to annuitize a part of his wealth $k_{1}$. Starting from period $t=2$ he only solves a consumption/saving problem. ${ }^{21}$ We denote the annuity income of a retiree starting from period $t=2$ as $n$, where $n=n_{1}+\Delta$, and $\Delta$ is newly acquired annuity income in period $t=1$. Note that annuity investments are irreversible, i.e., retirees receive $\Delta$ every period as long as they are alive. The price of annuity $\tilde{p}^{a}$ is determined as follows:

$$
\tilde{p}^{a}=\gamma \sum_{t=1}^{T-1} \frac{S_{t+1 \mid 1}}{(1+r)^{t}} .
$$

Here $S_{t+1 \mid 1}$ is the probability an agent survives to age $t+1(t=1, \ldots, T-1)$ conditional on being alive in period 1. It has the following relationship with per-period survival probabilities $s_{t}: S_{j \mid 1}=s_{2} s_{3} \ldots s_{j}$.

We model two types of frictions in the private annuity market. First, there is a load denoted as $\gamma$ in Equation (18). It represents the discrepancy between the actual and actuarially fair annuity prices for an individual with average mortality. It arises because of administrative costs and adverse selection.

Second, there is a minimum purchase requirement, i.e., a retiree cannot buy an arbitrarily small annuity income flow. This reflects an important feature of the market: insurance companies usually put a restriction on minimum premiums for a life annuity. We denote the minimum purchase requirement as $\bar{n}$, thus $\Delta \geq \bar{n}$, and the minimum premium is $\bar{n} \tilde{p}^{a}$.

\subsection{Calibration}

Retirees enter the model at the age of 65 (corresponding to $t=1$ ) and can live at most to age 95 (i.e., the maximum lifespan is $T=30$ ). We use the Social Security life tables to construct survival probabilities $s_{t}, t=1, \ldots, 30$.

\footnotetext{
${ }^{21}$ Pashchenko (2013) proves that in a retirement saving model with no uncertainty (except for survival uncertainty) an agent always chooses to annuitize only once in the first period.
} 
We take the initial distribution of retirees by total wealth and annuity income from the Health and Retirement Study dataset (HRS). The HRS is a nationally representative sample of individuals over the age of 50 . We use the RAND Version $\mathrm{P}$ of this dataset. To create the initial distribution we use retirees aged 64-66 in this dataset to increase the number of observations. Initial wealth $\left(k_{1}\right)$ includes the value of housing and real estate, vehicles, value of business, IRAs, Keoghs, stocks, bonds, checking, saving and money market accounts, minus mortgages and other debts. Preexisting annuity income $\left(n_{1}\right)$ corresponds to income from a Social Security pension.

We use the EZW parametrization of preferences described in Section 3. We assume the following parameter values. To set risk aversion, IES, discount factor and bequest parameters, we use parametrization from Pashchenko and Porapakkarm (2019), who adjust these parameters to match labor supply and saving behavior over the life-cycle. Specifically, we set the discount factor $\beta$ to 0.96 , the risk aversion parameter $\sigma$ to 4 , and the IES parameter $\alpha$ to $2 / 3$. Note that in their estimation, risk aversion exceeds the inverse of the IES. We also consider how our quantitative results change when the opposite is true.

We adjust bequest parameters so that the marginal propensity to bequeath (MPB) and the bequest threshold in our model are equal to 0.97 and $\$ 3,600$, respectively (values estimated by Pashchenko and Porapakkarm, 2019). The threshold and the MPB can be expressed as functions of parameters $\eta$ and $\phi$ in a simple two-period consumption-savings model (see De Nardi et al. (2010) and Pashchenko (2013) for more details). They have the following interpretation: only people whose wealth is above the threshold will leave a bequest (i.e., have an operational bequest motive) and 97 cents of every dollar above the threshold will be considered as potential bequests. ${ }^{22}$ We set the weight of consumption in the intra-period utility function $\xi$ to $0.5 .^{23}$

We set the load in annuity price $\gamma$ to 1.1 based on the estimates of Mitchell et al. (1999). Following Pashchenko (2013) we set the minimum purchase requirement $\bar{n}$ to $\$ 2,500$. She

\footnotetext{
${ }^{22}$ The corresponding values of $\eta$ and $\phi$ are $10^{-4}$ and 120,000 , respectively.

${ }^{23}$ Our results are robust to alternative values of this parameter. Changing the value of this parameter, while keeping everything else the same, changes the MPB and bequest threshold. However, once other parameters are adjusted to reset the MPB and threshold to the targeted values, the effect of the change in $\xi$ becomes insubstantial.
} 
shows that this number produces a minimum premium consistent with that set by large insurance companies.

\subsection{Results}

Figure 1 displays the results of our simulations. The top panel shows the percentage of individuals who purchase annuities at the beginning of retirement as a function of intra-period utility of being alive $(b)$, while the bottom panel shows the corresponding change in the value of a statistical life (VSL).
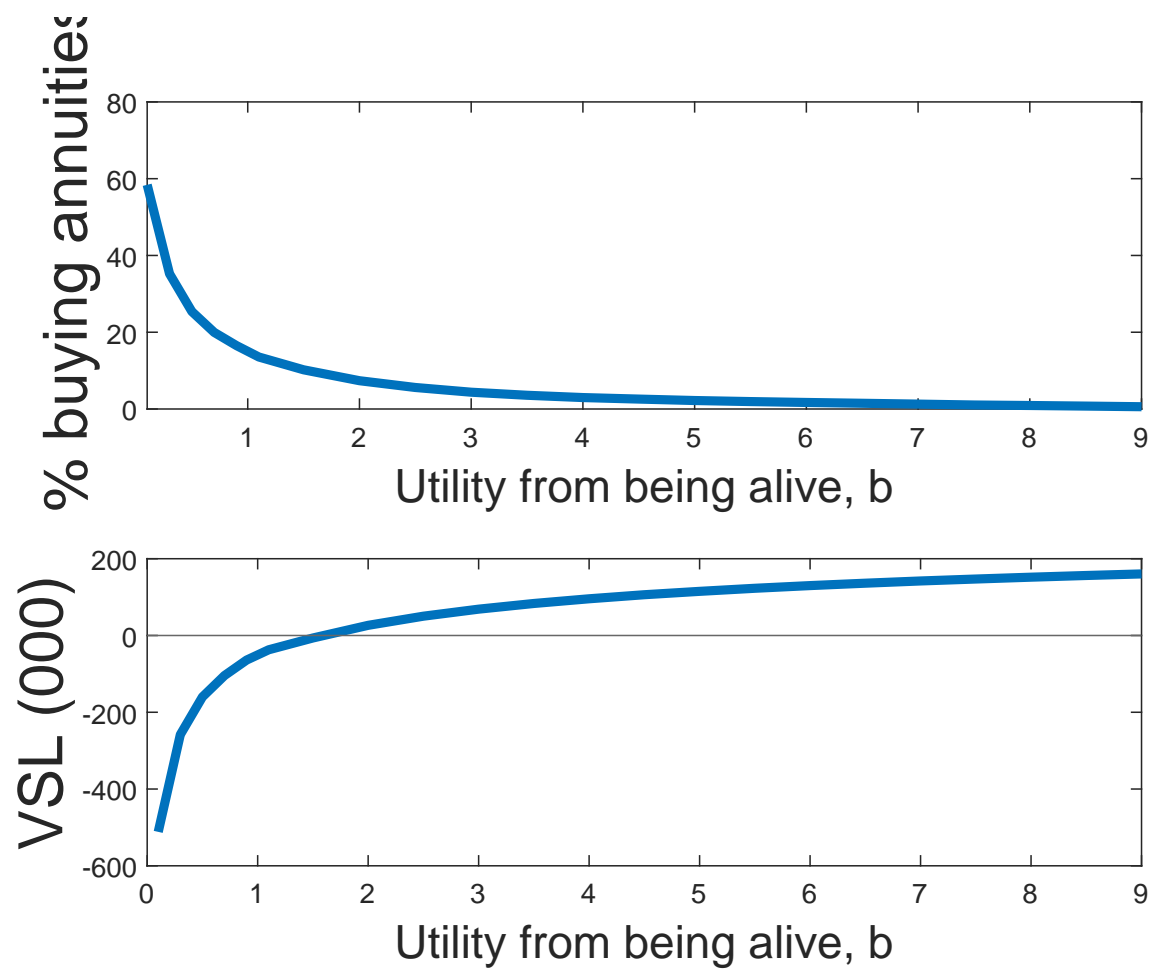

Figure 1: Annuity demand and the value of life when risk aversion is above 1/IES. Top panel: the percentage of retirees buying annuities. Bottom panel: VSL in thousand of dollars.

When $b$ is close to zero, almost $60 \%$ of retirees annuitize at least some part of their wealth. ${ }^{24}$ This situation also corresponds to a negative VSL, i.e., the state of being alive is valued less than the state of being dead. As $b$ increases, the VSL increases, while at the

\footnotetext{
${ }^{24}$ In the canonical life-cycle model this number would be $100 \%$. Our model, however, features several impediments to annuitization; specifically, preannuitized wealth, market frictions, and bequest motives. Note that despite all these impediments, more than half of retirees choose to annuitize.
} 
same time, demand for annuities goes down. The VSL becomes positive once $b$ is close to 2 , and in this situation only around $10 \%$ of people buy annuities. Increasing $b$ to around 6 almost entirely eliminates the demand for annuities. Note that the corresponding VSL is less than $\$ 200 \mathrm{~K}$.

We consider next a situation when risk aversion is below the inverse of the IES. We decrease the coefficient of risk aversion to 0.5 (compared to the benchmark value of 4 ), which is now below 1/IES (equal to 0.67 ), while keeping all other parameters unchanged.

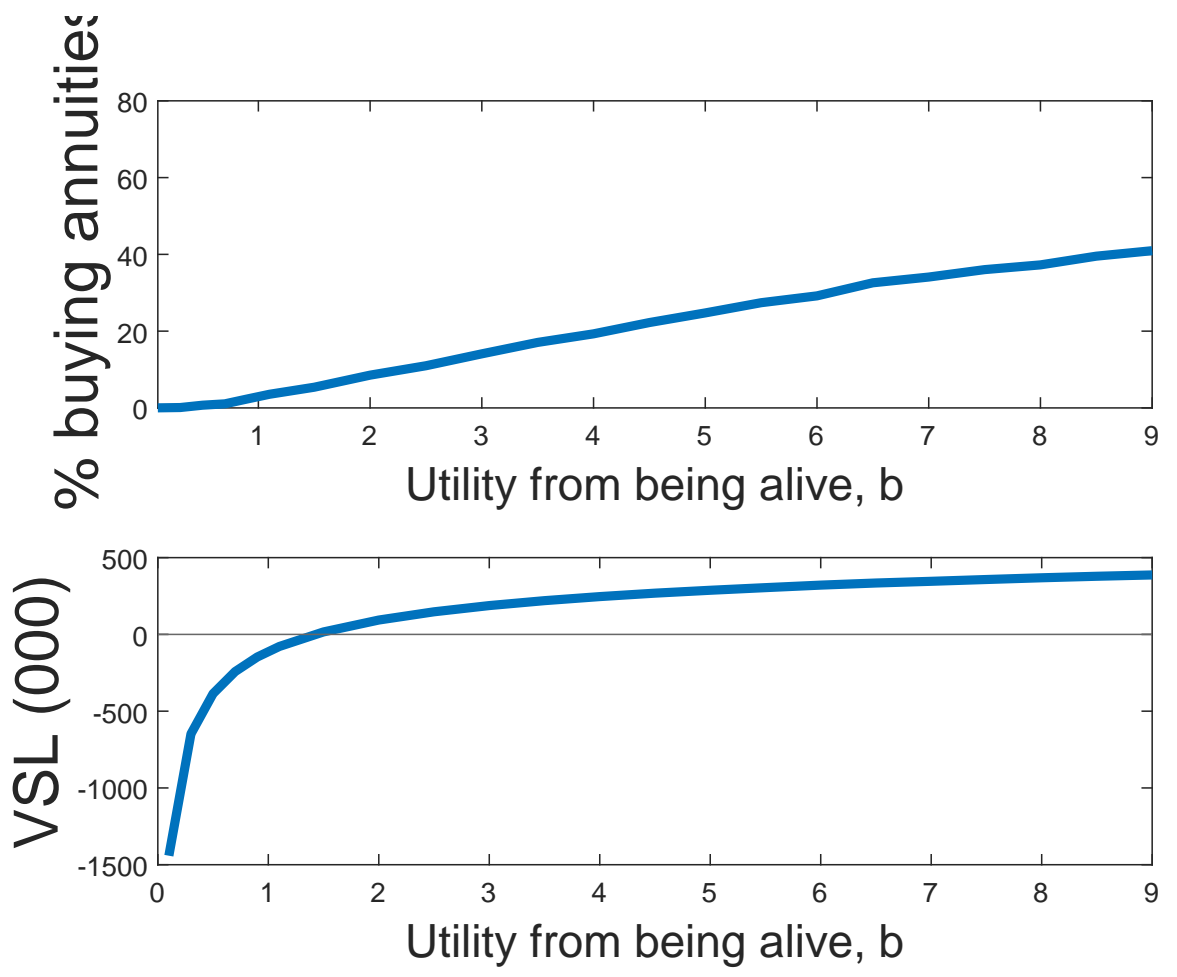

Figure 2: Annuity demand and the value of life when risk aversion is below 1/IES. Top panel: the percentage of retirees buying annuities. Bottom panel: VSL in thousands of dollars.

Figure 2 displays the results when using this new parametrization. The top panel looks very different from the previous case: now when $b$ is zero, no retirees buy annuities. However, as $b$ increases, more and more people start annuitizing. For example, when $b$ is close to 9 , almost $40 \%$ of retirees purchase private annuities. This is in sharp contrast with the previous case: when risk aversion was above 1/IES, a value of $b$ close to 9 resulted in zero annuity demand. ${ }^{25}$ 
To summarize, the results of this section reinforce our earlier conclusion: when we disentangle an agent's attitude toward risk and intertemporal fluctuations, utility of being alive affects the demand annuities. Moreover, this mechanism is quantitatively important: using the EZW parametrization with risk aversion exceeding the inverse of the IES, we show that the demand for annuities is substantially lower when the VSL is positive compared to the situation with the negative VSL. ${ }^{26}, 27$

\subsection{Implications for the debate about early versus late resolution of uncertainty}

When people have standard additive expected utility they demonstrate indifference to the timing of the resolution of uncertainty. In a simple two-period example this means they are indifferent between two lotteries, $\mathrm{A}$ and $\mathrm{B}$, that can be described as follows. Let both lotteries have the same expected payoff. In lottery A, in the first period the outcomes for both the current and future period are revealed, i.e., all uncertainty is resolved. In lottery $\mathrm{B}$, the outcome for the second period is not known until the second period arrives. ${ }^{28}$

In the case of non-expected utility, people are no longer indifferent between these two lotteries. Specifically, in the case of EZW preferences, when risk aversion exceeds the inverse of the IES, people are said to demonstrate preference for early resolution of uncertainty, i.e., in our example, lottery A brings higher ex-ante utility than lottery B. In contrast, when

\footnotetext{
${ }^{25}$ Note that VSL in the bottom panel of Figure 2 increases in $b$. This does not necessarily have to be the case, as we demonstrated theoretically in Section 2.

${ }^{26} \mathrm{It}$ is important to mention that empirical estimates of the VSL are typically above the value that produces almost zero annuity demand in our simulations (which is less than $\$ 200 \mathrm{~K}$ ). Viscusi (1993) provides an extensive review documenting that the estimates vary from $\$ 1$ million to $\$ 16$ million (in 1990 dollars). US government agencies (Department of Transportation, Food and Drug Administration, Environmental Protection Agency) use a VSL between \$1-10 million in their analyses involving mortality risk (Robinson, 2007).

${ }^{27}$ Consistent with these results, Bommier et al. (2020) show that a quantitative model with risk-sensitive preferences and positive VSL can be calibrated to match low annuity demand. Their calibration implies preferences for early resolution of uncertainty.

${ }^{28}$ The comparison between the two lotteries is made under the assumption that people cannot do anything, whether they know the outcomes early or not, i.e., they cannot re-optimize.
} 
risk aversion is below the inverse of the IES, late resolution of uncertainty is preferred, i.e., lottery B brings higher expected utility.

In this light, we can restate our finding as follows: when people prefer early resolution of uncertainty, the annuity puzzle can to a significant degree be explained by the fact that people value life. We argue that one reason why theoretical models starting with Yaari (1965) consistently over-predict annuity demand is that in these models people are typically indifferent to the timing of uncertainty resolution and do not necessarily prefer living to dying.

A number of studies show that people are not indifferent to the timing of uncertainty resolution, but the question of whether early or late resolution is preferred is not entirely resolved. Three branches of literature discussed in the introduction provide evidence that early resolution is preferred; specifically, studies that estimate an Euler equation using consumption data, experimental studies and macro finance literature (e.g., Bansal and Yaron, 2004; Brown and Kim, 2014; Vissing-Jorgensen and Attanasio, 2003). However, there are some studies pointing in the other direction. In particular, several studies in health economics suggest that people's attitude towards testing for serious diseases may signal preferences for late resolution (e.g., Oster et al., 2013).

This suggests another angle in which our results can be viewed. Specifically, we can contribute to the debate on whether early or late resolution of uncertainty is preferred. We show that one well-documented empirical fact (the VSL is high) can explain another well-known empirical regularity (low demand for annuities) in a framework where early resolution of uncertainty is preferred. Therefore we suggest that the annuity puzzle in combination with the high VSL estimates can be considered as additional evidence that people prefer early resolution of uncertainty.

\section{Conclusion}

In this paper, we study the relationship between the value of life and the demand for assets with survival-contingent payoffs. Two key features of our approach compared to a standard portfolio choice problem with survival uncertainty is that i) we enforce the restriction that living is preferred to dying by allowing for non-pecuniary utility of being 
alive, ii) we allow for a more general preference specification where attitudes towards risk and intertemporal fluctuations can be separated.

We show theoretically that increasing non-pecuniary benefits from being alive can increase or decrease the demand for annuities depending on whether people are more averse to risk or to intertemporal fluctuations. When safety is of greater concern than intertemporal stability, people buy less annuities when utility of being alive increases.

To illustrate this quantitatively, we use Epstein-Zin-Weil parametrization of preferences and simulate annuity demand in a retirement saving models using the data from the HRS. We show that when risk aversion exceeds the inverse of the IES, the fraction of retirees buying annuities quickly decreases as life becomes more valuable. Moreover, when other common impediments to annuitization are present, the demand for annuities is nearly eliminated for values of VSL which are positive but not necessarily very large.

We can rephrase our findings in two ways. First, the well-known annuity puzzle can be at least partially explained by a combination of two factors: i) the value of life is positive and sufficiently large, ii) people are more averse to risk than to intertemporal fluctuations.

Second, the annuity puzzle provides evidence that people prefer early resolution of uncertainty, i.e., that risk aversion is above the inverse of the IES. This is because when life is valuable, early resolution of uncertainty must be preferred in order to account for this puzzle. 


\section{References}

[1] Attanasio, O., Weber, G., 1989. "Intertemporal Substitution, Risk Aversion and the Euler Equation for Consumption". Economic Journal, 99, 59-73

[2] Andersson, H., Treich, N., 2011, "The Value of a Statistical Life" in "Handbook in Transport Economics", Edward Elgar, Cheltenham, UK.

[3] Bansal, R., Yaron, A., 2004. "Risks for the Long-Run: A Potential Resolution of Asset Pricing Puzzles." Journal of Finance, 54, 1481-1509

[4] Bommier, A., Harenberg, D.,Le Grand, F., O’Dea, C., 2020. Recursive Preferences, the Value of Life, and Household Finance. Cowles Foundation Discussion Paper N 2231

[5] Bommier, A., Villeneuve, B., 2012. Risk Aversion and the Value of Risk to Life. Journal of Risk and Insurance, Vol. 79, No. 1, pp. 77-103

[6] Brown, A., Kim, H., 2014 "Do Individuals Have Preferences Used in Macro-Finance Models? An Experimental Investigation", Management Science, 60, 939-958

[7] Chen, X., Favilukis, J., Ludvigson, S., 2013." An Estimation of Economic Models with Recursive Preferences". Quantitative Economics, 4, 39-83

[8] Cordoba, J.C., Ripoll, M., 2017, "Risk Aversion and the Value of Life", Review of Economic Studies, vol.84(4), pp. 1472-1509.

[9] De Nardi, M., 2004. "Wealth Inequality and Intergenerational Links". Review of Economic Studies, 71(7), 743-768

[10] De Nardi, M., French, E., Jones, J., 2010., Why Do the Elderly Save? Journal of Political Economy, 118(1), pp.39-75.

[11] De Nardi, M., Pashchenko, S., Porapakkarm, P., 2018. The Lifetime Cots of Bad Health. NBER Working Paper No. 23963

[12] Dushi, I., Webb, A., 2004. Household Annuitization Decisions: Simulations and Empirical Analysis. Journal of Pension Economics and Finance 3(2), 109-143 
[13] Epstein, L., Zin, S, 1989. Substitution, Risk Aversion, and the Temporal Behavior of Consumption and Asset Returns: A Theoretical Framework, Econometrica, 57(4), pp 937-969

[14] Eslami K., Karimi, S., 2019. Health Spending: Luxury or Necessity? Mimeo, Ryerson University

[15] Fonseca, R., Michaud, P-C., Kapteyn, A., Galama, T., 2020. Accounting for the Rise in Health Spending and Longevity. Journal of the European Economic Association, forthcoming

[16] Guvenen, F., 2009. A Parsimonious Macroeconomic Model for Asset Pricing. Econometrica, Vol. 77, N6, pp 1711-1750

[17] Hall, R., Jones, C., 2007, "The Value of Life and the Rise in Health Spending", Quarterly Journal of Economics, vol.122(1), pp. 39-72.

[18] Hansen, L., Sargent, T., 1995. Discounted Linear Exponential Quadratic Gaussian Control. IEEE Transactions on Automatic Control, 40(5), pp 968-971.

[19] Huang, D., Shaliastovich, I., 2013. "Risk Adjustment and the Temporal Resolution of Uncertainty: Evidence from Options Markets". Mimeo, University of Pennsylvania

[20] Hubbard, G., Skinner, J., Zeldes, S., 1994. The Importance of Precautionary Motives in Explaining Individual and Aggregate Saving. Carnegie-Rochester Conference Series on Public Policy, 40(1), pp. 59

[21] Inkman J., Lopes, P., Michaelides, A., 2011. How Deep is the Annuity Market Participation Puzzle? Review of Financial Studies, 24(1), pp. 279-319.

[22] Kellerman, S., Lehman,J., Lansky, A., Stevens, M., Hecht, F., Bindman, A., Wortley, P., 2002. "HIV testing within at-risk populations in the United States and the reasons for seeking or avoiding HIV testing". Journal of Acquired Immune Deficiency Syndromes, $31,202-210$

[23] Kaplan, G.,Violante, G. 2014. A Model of the Consumption Response to Fiscal Stimulus Payments. Econometrica, 82(4), pp 1199-1239. 
[24] Kreps, D., Porteus, E., 1978. "Temporal Resolution of Uncertainty and Dynamic Choice Theory". Econometrica, 46, 185-200

[25] Krueger, D., Ludwig, A., 2019. Optimal Taxes on Capital in the OLG Model with Uninsurable Idiosyncratic Income Risk. Mimeo, University of Pennsylvania

[26] Lockwood, L., 2012. Bequest Motives and the Annuity Puzzle. Review of Economic Dynamics, 15(2), pp. 226-243

[27] Love. D., 2017. Countercyclical Retirement Accounts. European Economic Review, Vol 98, pp 38-42

[28] Malloy, C., Moskowitz, T., Vissing-Jorgensen, A., 2009. "Long-Run Stockholder Consumption Risk and Asset Returns". Journal of Finance, LXIV, N 6

[29] Meissner, T., Pfeiffer, P., 2018. "Measuring Preferences Over the Temporal Resolution of Consumption Uncertainty". Unpublished manuscript

[30] Murphy, K., Topel, R., 2006, "The Value of Health and Longevity", Journal of Political Economy, vol.114, N51, pp. 871-904

[31] Mitchell, O. S., Poterba, J.M., Warshawsky, M.J., Brown, J.R., 1999. New Evidence on the Money's Worth of Individual Annuities. American Economic Review 89(5), pp.1299-1318

[32] Nygaard, N., 2019. Causes and Consequences of Life Expectancy Inequality. Mimeo, University of Houston

[33] Ozkan, S., 2017. Preventive vs. Curative Medicine: A Macroeconomic Analysis of Health Care over the Life Cycle. Mimeo, University of Toronto.

[34] Oster, E., Shoulson, D., Dorsey, R., 2013. "Optimal Expectations and Limited Medical Testing: Evidence from Huntington Disease", American Economic Review, 103, 804-830

[35] Pashchenko, S., 2013. Accounting for Non-Annuitization. Journal of Public Economics, 98, pp. $53-67$ 
[36] Pashchenko, S., Porapakkarm, P., 2019. Accounting for Social Security Claiming Behavior. Mimeo, University of Georgia

[37] Robinson, L., 2007. How US Government Agencies Value Mortality Risk Reductions, Review of Environmental Economics and Policy, 1(2), pp.283-299.

[38] Rosen, S., 1988, "The Value of Changes in Life Expectancy", Journal of Risk and Uncertainty, vol.I, pp.285-304.

[39] Traeger, C., 2014, "Capturing Intrinsic Risk Attitude", mimeo, University of California Berkely

[40] Viscusi, K., 1993, "The Value of Risks to Life and Health", Journal of Economic Literature, vol.31(4), pp.1912-1946.

[41] Vissing-Jorgensen, A., Attanasio, O., 2003. "Stock Market Participation, Intertemporal Substitution and Risk Aversion", American Economic Review Papers and Proceedings, 93, 383-391

[42] Weil, P., 1990, "Non-expected Utility in Macroeconomic?", Quarterly Journal of Economics, vol.105, pp.29-42.

[43] Yaari, M., 1965. "Uncertain Lifetime, Life insurance, and the Theory of the Consumer". Review of Economic Studies, 32, 137-150

[44] Yogo, M., 2006, "A Consumption-based Explanation of Expected Stock Returns", Journal of Finance, vol.LXI, N2, pp.539-580.

[45] Yogo, M., 2016. Portfolio Choice in Retirement: Health Risk and the Demand for Annuities, Housing, and Risky Assets. Journal of Monetary Economics, Vol 80, pp $17-34$. 